\title{
Effect of Different Concentration of Disinfectant Incorporated on Hardness of Heat Cured Acrylic Denture Base
}

\author{
Lateef E.A. Al-Jorani
}

(Assistant Professor) - BDS. MSc. PhD. Medical Technicl Institute / Middle Technical University

Zahraa Nazar Alwahab

(Assistant Professor)- BDS. MSC. College of Health and Medical Technologies/ Middle Technical University

\section{ABSTRACT}

Background: The removable appliances have played an important role in routine prosthodontics and orthodontics for centuries. When the appliances related diseases occur, several approaches have been suggested to manage the situation.

Materials and methods: Forty samples of heat cured acrylic were fabricated, they were divided into four groups according to the quantity of chlorhexidine incorporated with the liquid of acrylic (10 samples per each group), and these groups are:

Group1: control group mixing heat cure acrylic only (liquid is monomer only)

Group2: mixing 3/4 heat cure acrylic liquid with $1 / 4$ chlorehexidine.

Group3: mixing $1 / 2$ heat cure acrylic liquid with $1 / 2$ chlorehexidine.

Group4: $1 / 4$ mixing heat cure acrylic liquid with 3/4 chlorehexidine.

Results: The results of the present study found that the highest shore $D$ Hardness number was for the control group with no addition of chlorhexidine, while the lowest Shore D Hardness number was for group 4 (1/4 mixing heat cure acrylic liquid with $3 / 4$ chlorehexidine).

Conclusion: The results revealed a reduction in hardness with increase in the percentage of chlorhexidine addition to monomer. key words: Shore D Hardness, heat cured acrylic, chlorhexidine

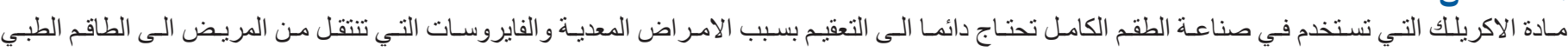

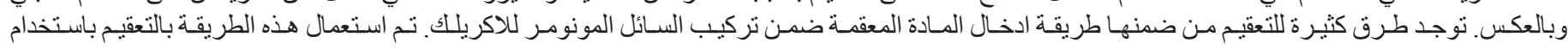

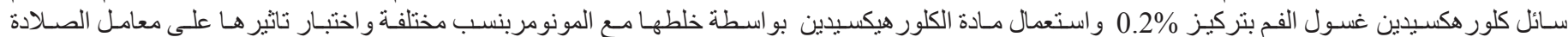

\section{INTRODUCTION}

The removable appliances have played an important role in routine prosthodontics and orthodontics for centuries. They are simple to fabricate, easy to be modified and easy to maintain. Despite all their benefits, these appliances can compromise the oral health ${ }^{(1)}$, when they not cleaned and maintained well ${ }^{(2)}$. When the appliances related diseases occur, several approaches have been suggested to manage the situation. One approach is to use polymeric systems that enable controlled release of medicaments ${ }^{(3)}$. In such an approach, a prolonged therapeutic approach effect may achieved by replacing high systemic dose with slow releasing lower local dose ${ }^{(4)}$.

The awareness for the need of disinfection in cross - contamination during the dental procedures for dentists, dental technicians has been increased due to the high prevalence of infectious diseases such as AIDS and Hepatatis $\mathrm{B}^{(5)}$.

Many systems have been developed to incorporate medications into removable appliances. The simplest way was to use them within the soft liners or tissue conditioners ${ }^{(6)}$, but these short term effects and the maintenance requirements make this system unfavorable. To overcome such problems, researchers have tried to incorporate medications into polymethylmethacrylate ${ }^{(4)}$ or the cold cured polyethyl methacrylate /tetrahydrofurfuryl methacrylate polymer bases ${ }^{(3)}$. The examples of these medications
النتائج: مع زيادة تركيز مادة الكلور هيكسيدين نتج عن ذلك نقصان الصلادة لمادة الاكريلك. are fluconazole and chlorhexidine, since it has been shown that incorporation of them into polymethyl methacrylate, they retain their therapeutic dose for up to 28 days ${ }^{(7)}$. On the other hand, there are some uncertainties regarding the effect of such techniques on the mechanical properties of the acrylic resin. The particles of chlorhexidine may be dissolved and results in porosity of the acrylic base ${ }^{(8)}$. It has been noticed that these additions may have adverse effects on the mechanical properties of cold cured acrylic ${ }^{(9)}$.

\section{MATERIALS AND METHODS \\ Samples Preparation:}

Heat cured acrylic used in this study (Vertex Netherland).

\section{Heat cure acrylic samples preparation:}

Wax plate $(65 \mathrm{~mm}$ long, $5 \mathrm{~mm}$ wide and $2 \mathrm{~mm}$ high in dimensions) ${ }^{(10)}$ were prepared and fixed into flask. Plaster slurry was prepared and poured in the lower half of flask. Before the plaster in the lower half of the flask was harden, the glass plate, was loaded and wax plate placed over the plaster, so that the level of the wax plate would be with the level of the plaster. When the plaster reached its initial set, it was coated with the separating medium (cold mold seal). Then the upper half of the flask was positioned on the lower half and a second mix of dental plaster was poured into the flask. After completing the setting of the plaster, wax elimination, was done by immersing 
the flask in boiling water for 4 minutes. Then the flask was opened, washed with boiled water to remove the remaining wax. Then it was allowed to cool, the flask opened again and the surface of the mold was coated with the separating medium. Heat cure acrylic powder was mixed with the liquid in a proper polymer monomer ratio of $3: 1$ by volume for 45 seconds at room temperature (control group), while in the other test groups, the monomer was mixed with chlorhexidine wouth wash (corsodyl $0.2 \%$ gsk, GlaxsoSmithKline, Consumer HealthCareTrading Limited, Brentford, TW8 9GS, UK) according to sample grouping.

A total of 40 samples were prepared and used in this study

The samples were divided into four groups, each group consists of 10 samples according to different ratio of chlorehexidine used:-

Group1: control group mixing heat cure acrylic only (liquid is monomer only)

Group2: mixing 3/4 heat cure acrylic liquid with $1 / 4$ chlorehexidine. $(3 \mathrm{ml}$ monomer with $1 \mathrm{ml}$ chlorehexidine).

Group3: mixing 1/2 heat cure acrylic liquid with $1 / 2$ chlorehexidine. (2 $\mathrm{ml}$ monomer with $2 \mathrm{ml}$ chlorehexidine).

Group4: 1/4 mixing heat cure acrylic liquid with $3 / 4$ chlorehexidine. .(1 ml monomer with $3 \mathrm{ml}$ chlorehexidine).

The container was left until it reached the dough stage, (when the mixture separates from the wall of the container). The mixture was packed into the plaster mould, the two halves of the flask were closed together, and then the flask assembly was placed into the clamp to allow the resin dough to flow evenly throughout the mould. Then the acrylic was curing for one hour.

\section{Finishing of the acrylic resin samples:-}

The acrylic plates were then removed from the flask and hand finished using acrylic and stone burs and polished with pumice and rough in dental lath.

\section{Shore D Hardness Number Test}

A Shore D device used to measure the surface hardness number of each sample.

\section{RESULTS}

Table 1 : Mean, SD, Min, Max of Shore D Hardness Number

\begin{tabular}{|c|c|c|c|c|}
\hline Statistic & Group 1 & Group 2 & Group 3 & Group 4 \\
\hline Mean & 88.82 & 84.24 & 83.92 & 77.01 \\
\hline SD & 0.405 & 0.788 & 0.535 & 1.262 \\
\hline SE & 0.128 & 0.249 & 0.169 & 0.399 \\
\hline Min & 87.9 & 83.2 & 83.1 & 74.9 \\
\hline Max & 89.3 & 84.8 & 84.8 & 78.8 \\
\hline
\end{tabular}

Table 2 : Post Hoc Tests

Tukey HSD

\begin{tabular}{|c|c|c|c|c|c|}
\hline \multirow{2}{*}{ Groups } & Mean difference & Std.Error & Sig. & \multicolumn{2}{|c|}{ 95\% Confidence Interval } \\
\cline { 2 - 6 } & & & Lower Bound & Upper Bound \\
\hline $1 \& 2$ & $4.5800^{*}$ & .36488 & .000 & 3.5973 & 5.5627 \\
\hline $1 \& 3$ & $4.9000^{*}$ & .36488 & .000 & 3.9173 & 5.8827 \\
\hline $1 \& 4$ & $11.8100^{*}$ & .36488 & .000 & 10.8273 & 12.7927 \\
\hline $2 \& 3$ & .3200 & .36488 & .817 & -.6627 & 1.3027 \\
\hline $3 \& 4$ & .36488 & .000 & 6.2473 & 8.2127 \\
\hline
\end{tabular}




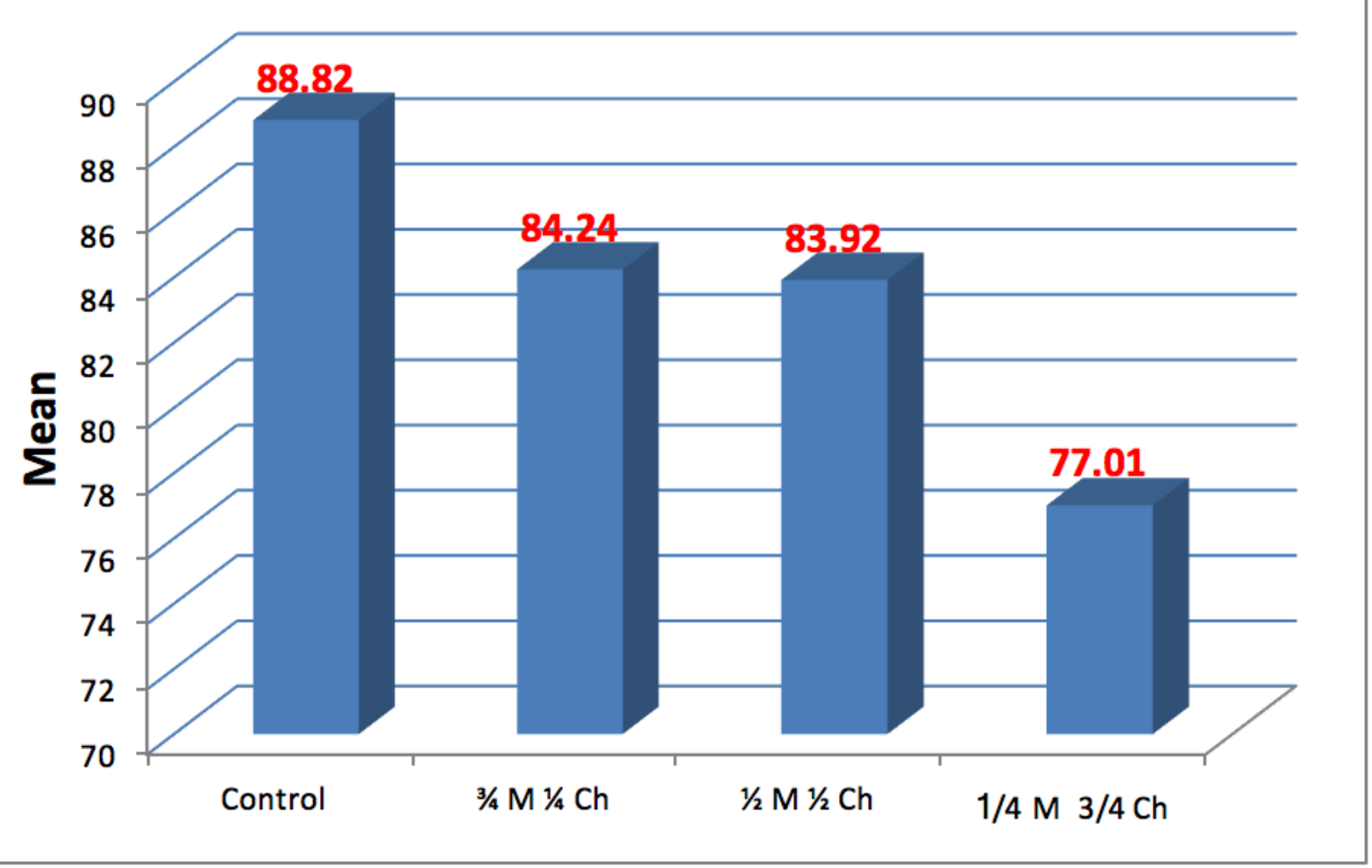

\section{DISCUSSION}

The need to disinfect prosthesis has resulted in the wide spread search for disinfectant agents that are innocuous to the prosthesis surface. Various chemical agents are used in dental prosthesis disinfection, i.e., chlorine, iodophors, aldehyde compounds, and chlorhexidine ${ }^{(5)}$.

Hardness testing is done by applying a standard force or a standard weight to an indenter. This produces a symmetrically shaped indentation that can be measured under a microscope for depth, area, or width of the indentation produced. The indentation dimensions are then related to

hardness values. With a fixed load applied to a standardized indenter, the dimensions of the indentation vary inversely with the resistance to penetration of the material tested.

Thus lighter loads are used for softer materials. (11). The use of disinfectant may alter the surface of acrylic resins ${ }^{(12)}$.

The Chlorhexidine is a bisbiguanide formulation with cationic properties. Such molecule is symmetric with two chlorophenyle rings and two bigunide groups connected together by a central hexamethylene chain. It is a strong base and is most stable in the form of salts. The most common preparation is the digluconate salt because of its water solubility ${ }^{(13)}$.

Reports in the literatures using experimental testing protocols that would allow a comparison with this study are uncommon.
The results of the present study revealed that the highest Shore D Hardness Number was for the Control group followed by group 2, group 3 and group 4 .

As the study was specifically looking at the mechanical properties of the PMMA acrylic, the powder: monomer ratio of each group was kept consistent.

The results revealed a reduction in hardness with increase in the percentage of chlorhexidine addition to monomer. This reduction could be attributed to the release of chlorhexidine components from acrylic resin. They found that Chlorhexidine and other antimicrobial agents have been shown to be released at relatively high rates from various methacrylate polymers ${ }^{(14)}$.

The results are in agreement with ${ }^{(15)}$, a study found that the incorporation of chlorhexidine to acrylic resin significantly decrease the hardness number of acrylic.

This in agreement with ${ }^{(16)}$, a study on the effect of water and drug incorporation into monomer. They found that leacking of chlorehexidine lead to a reduction in mechanical properties of acrylic resin.

The present study is in agreement with ${ }^{(2)}$, a study explained this reduction in Shore D Hardness Number because the mechanical properties of denturebase polymers could be affected by an aqueous environment. It has also been shown that dilution of bioactive compounds can also have an effect on the properties of the acrylic once the specimens. 


\section{REFERENCES}

1. Tawse- Smith A, Rivillas CC, Orozco PS, Diaz JE, Pack AR. Clinical effects of removable acrylic appliance design on gingival tissue: a short term study. J Inter Academ of Perio $2001 ; 3: 22-7$.

2. Al - Haddad A, Roudsari RV, Satterthwaite JD. Fracture toughness of heat cured denture base acrylic resin modified with Chlorhexidine and Fluconazole as bioactive compounds. J Dent 2014; 42: 180 - 184.

3. Patel MP, Cruchley AT, Coleman DC, Swai H, Braden M, Williams DM. A polymeric system for the intra - oral delivery of an anti - fungal agent. Bio 2001; 22: 2319 2324.

4. Ryalat S, Darwish R, Amin W. New form of administrating chlorhexidine for treatment of denture induced stomatitis. Ther Clin Risk Manag 2011; 7: 219-225.

5. Carvalho CF, Vanderlei AD, Salazar Marocho SM, Pereira SMB, Nogueira L, Arruda Paes - Junior. Acta Odontal Latinoom 2012; 25(3):255 - 260.

6. Wyre RW, Downes S. An in vitro investigation of the PEMA/ THFMA polymer system as a biomaterial for cartlige repair. Bio 2000; 21:335 - 343.

7. Chow CK, Matear DW, Lawrence HP. Efficacy of antifungal agents in tissue conditioners in treating Candidiasis. Gerodont 1999;16:110 - 118.

8. Amin WH, Al - Ali MH, Salim NA, Al - Tarawneh SK. Anew form of intraoral delivery of antifungal drugs for the treatment of denture - induced oral candidosis. Europ J of Dent 2009; 3: $257-266$.

9. Addy M, Handley R. The effects of the incorporation of chlorhexidine acetate on some physical properties of polymerized and plasticized acrylics. J Oral Rehab 1981; $155-163$.

10. Consani RLX, Folli BL, Nogueira MCF, Correr AB, Marcelo F. Mesquita MF. Effect of Polymerization Cycles on Gloss, Roughness, Hardness and Impact Strength of Acrylic Resins. Brazilian Dental Journal 2016; 27(2): 176-
180.

11. Sakaguchi R and Power JM. Craig's restorative dental material. 2012. 13th ed. ELSEVIER MOSBY 1600 John F. Kennedy Blvd.Ste 1800 Philadelphia, PA 19103-2899. Ch 5 pp89-90.

12. Machado AL, Giampaolo ET, Moreno A, Iyda MG, Rezende MC, Haddad MF. Effect of disinfection and storage on the flexural strength of ocular prosthetic acrylic resins.

Gero dontology 2012; 29: e838 - 844 .

13. Sajjan P, Laxminarayan N, Prakash Kar P, sajjanar M. Chlorhexidine as an Antimicrobial Agent in Dentistry - A Review. OHDM 2016 ;15 (2): 93 - 102.

14. Hiraishi N, Yiu CKY, King NM, Tay FR, Pashley DH. Chlorhexidine release and water sorption characteristics of chlorhexidine-incorporated hydrophobic/hydrophilic resins. Dent Mater 2008; 24(10): 1391-1399.

15. Salim N1, Moore C, Silikas N, Satterthwaite J, Rautemaa R. Candidacidal effect of fluconazole and chlorhexidine released from acrylic polymer. J Antimicrob Chemother. 2013 ;68(3):587-592.

16. Thaw M, Addy M, Handley R. The effects of drug and water incorporation upon some physical properties of cold cured acrylic. J Biomedical Materials Research. 1981;15(1): 2936. 